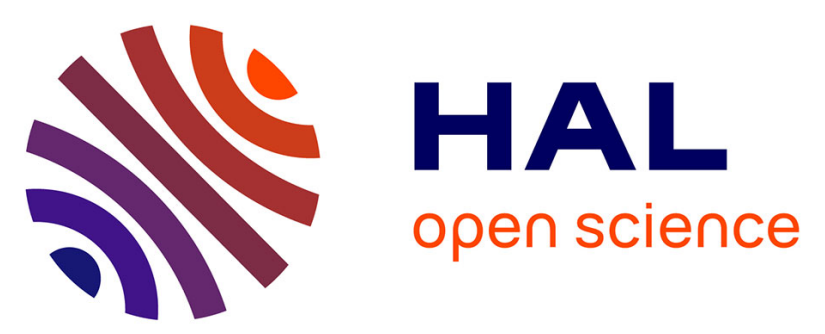

\title{
A water storage and release strategy for flood management based on transportation network with time delay
}

Houda Nouasse, Pascale Chiron, Bernard Archimède

\section{- To cite this version:}

Houda Nouasse, Pascale Chiron, Bernard Archimède. A water storage and release strategy for flood management based on transportation network with time delay. 2013 IEEE 18th Conference on Emerging Technologies \& Factory Automation (ETFA), Sep 2013, Cagliari, Italy. pp. 1-8. hal-00926529

\section{HAL Id: hal-00926529 \\ https://hal.science/hal-00926529}

Submitted on 9 Jan 2014

HAL is a multi-disciplinary open access archive for the deposit and dissemination of scientific research documents, whether they are published or not. The documents may come from teaching and research institutions in France or abroad, or from public or private research centers.
L'archive ouverte pluridisciplinaire HAL, est destinée au dépôt et à la diffusion de documents scientifiques de niveau recherche, publiés ou non, émanant des établissements d'enseignement et de recherche français ou étrangers, des laboratoires publics ou privés. 


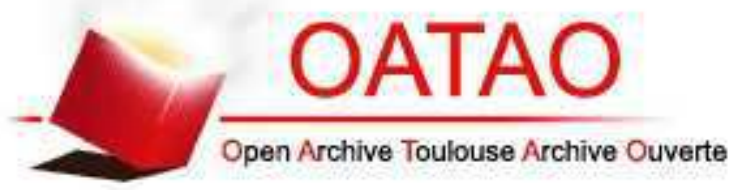

\section{Open Archive Toulouse Archive Ouverte (OATAO)}

OATAO is an open access repository that collects the work of Toulouse researchers and makes it freely available over the web where possible.

This is an author-deposited version published in: http://oatao.univ-toulouse.fr/ Eprints ID: 10028

\section{To cite this version:}

Nouasse, Houda and Chiron, Pascale and Archimède, Bernard A water storage and release strategy for flood management based on transportation network with time delay. (2013) In: 2013 IEEE 18th Conference on Emerging Technologies \& Factory Automation (ETFA), 10 September 2013 - 13 September 2013 (Cagliari, Italy). 


\title{
A water storage and release strategy for flood management based on transportation network with time delay
}

\author{
Houda Nouasse, Pascale Chiron, Bernard Archimède \\ University of Toulouse, INPT, ENIT, LGP, 65016 Tarbes, FRANCE, \\ houda.nouasse@enit.fr, pascale.chiron@enit.fr, bernard.archimede@enit.fr
}

\begin{abstract}
Today, with frequency and severity of extreme weather, flood management became in the world a major concern for governments. The engendered problems are relative to goods and persons safety. Their considerations require a predictive management involving storage and draw-off strategy with several flood areas in order to limit water heights to the downstream of streams. A good flood management requires a control not only of storage to avoid downstream problems but also of water release to protect the fertility of flood expansion areas which are most often based on growing areas. In the literature, numerous described works were done on flows modeling and management. The work presented in this paper, is interested in the quantitative management by means of floods expansion areas placed along the river and for which we have their location as well as their sizing. The performances of management depend on moment and on height of gates opening which influence on wave mitigation. The proposed management method is based on a dynamic mechanism from which the water volumes to be stored or draw-off in time are calculated.
\end{abstract}

\section{Introduction}

Flooding due to excessive rainfall and surface runoff can cause significant damages, properties loss and injuries around the world. October 20, 2012, heavy rains fell on the Pyrenean foothills. The flood of the Gave de Pau overwhelmed the bottom of Lourdes city and the sanctuary. In the night, Gave came out of his bed and the Grotto was flooded. The altar of the Grotto was literally submerged by water. To prevent these problems, river systems are increasingly equipped with means for detecting floods and floodplains sized and positioned according to the topography. Flood management requires increased reactivity as compared to other management methods based on planning where the necessary data are known a priori. Indeed, managers must take impor- tant decisions quickly in an uncertain context, because most of these floods are induced by abrupt climatic phenomena, and their magnitude are difficult to accurately assess. The integration of adapted digital tools to these crises is relevant and necessary to improve the decision-making [10], [15]. The difficulty is related to the choice of the optimization model associated to management method, which depends on device characteristics, data availability, goals to achieve and constraints to be satisfied. In the literature, different optimization techniques are proposed to help flood management among which we can mention: the linear programming [12],nonlinear programming [2], [5], multiobjective optimization [6] or genetic algorithms [4]. Some heuristics are also used to deal with this management, notably algorithms for flows maximizing [1], [3], [8]. Unfortunately, the management methods based on algorithms for flows maximizing do not take into account the transfer time of water volumes. Thus, the objective of this paper is to describe a method for managing storage and drawoff of volume dispatched in expansion areas, which are available along of a watercourse in a river system. The proposed method is based on transportation networks with time delay. The paper is organized as follows. Section 2 describes the flood-diversion area system. Section 3 describes the proposed approach to manage the flood. In section 4 , the simulation results during a flooding period are displayed and discussed. Finally, the conclusion summarizes the interest of the proposed flood lamination strategy combined to the 1D simulator and suggests some future works.

\section{Flood diversion area system}

A flood-diversion-area (FDA) system consists of a series of $n_{G}$ FDAs distributed along the river. A FDA is a floodplain area equipped with controlled gate. The gate opening creates depression waves that interfere with the flood wave to reduce peak flood discharges. To illustrate our approach we use a simplified example, with $n_{G}=3$, of a river as a benchmark. A river reach provide with three lateral floodplain area $\left(F D A_{1}, F D A_{2}, F D A_{3}\right)$ is assumed (see Figure 1 ). 
The river and the floodplains are separated by levees everywhere except at certain points where they are connected through a gate, $G_{r}, r=1, \cdots, n_{G}$. These vertical levees are high enough for avoiding overflow. For simulation purposes, this river is modelled using 1D Shallow water equations [7]. We assume that $\tau_{r}$ $\left(r=1, \cdots, n_{G}-1\right)$ is the transfer time from the gate $G_{r}$ to the following gate $G_{r+1}$.

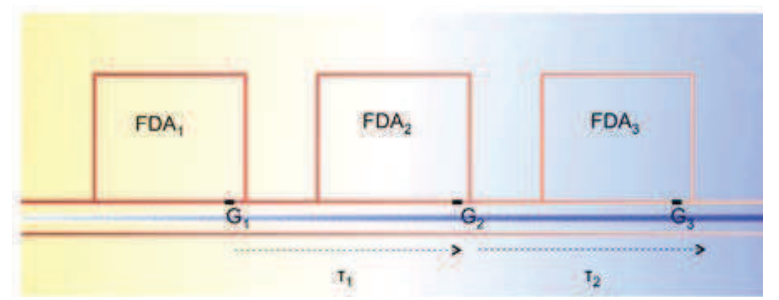

Figure 1. River with three lateral floodplain.

\section{Dynamic RGTM mechanism}

In previous work [13], in order to model our benchmark, we proposed the use of a static transportation network, where we assumed that $\tau_{r}=0, r=$ $1, \cdots, n_{G}-1$. The problem was formulated as a MinCost-Max-Flow problem that minimizes a linear cost function subject to the constraints of flow conservation and minimal and maximal capacities. In this formulation we tried to determine an optimal lamination flow that satisfies physical constraints required by a flood scenario and the optimization method management parameters. In order to improve this management method, we have studied the impact of time delay on an expanded temporized transportation network model [9], [11]. In this study [14], we focused on the evolution of the state of our flood-diversion area system at each $k T_{c}, k=0, \cdots, n$, in the horizon $H_{f}$, with $H_{f}=n \times T_{c}, n \in \mathbb{N}^{+}$.

The use of such a model requires that transfer times are static between two view points on the river while they depend on the flow-rate, which changes over time. Moreover, this kind of model, depending on the size of the time horizon $H_{f}$ and the period $T_{c}$, can lead to an oversize transportation network. Herein, in order to overcome these two points we propose a dynamic RGTM mechanism (see Figure 2), which allows enhancing the temporized network: more dynamic and suitable for various river sections with variable transfer time.

This mechanism is composed of a reduced transportation network $\mathbb{R} \mathbb{G}$ and a Temporization Matrix $(T M)$. The transportation network $\mathbb{R} \mathbb{G}$ enables water storage and draw-off and communicates with this matrix in order to store and to get the values of delayed flow. $T M$ is a $n \times 2 n_{G}$ matrix where each column represents the evolution of the gate or FDA discharges, and each line represents an instant of the

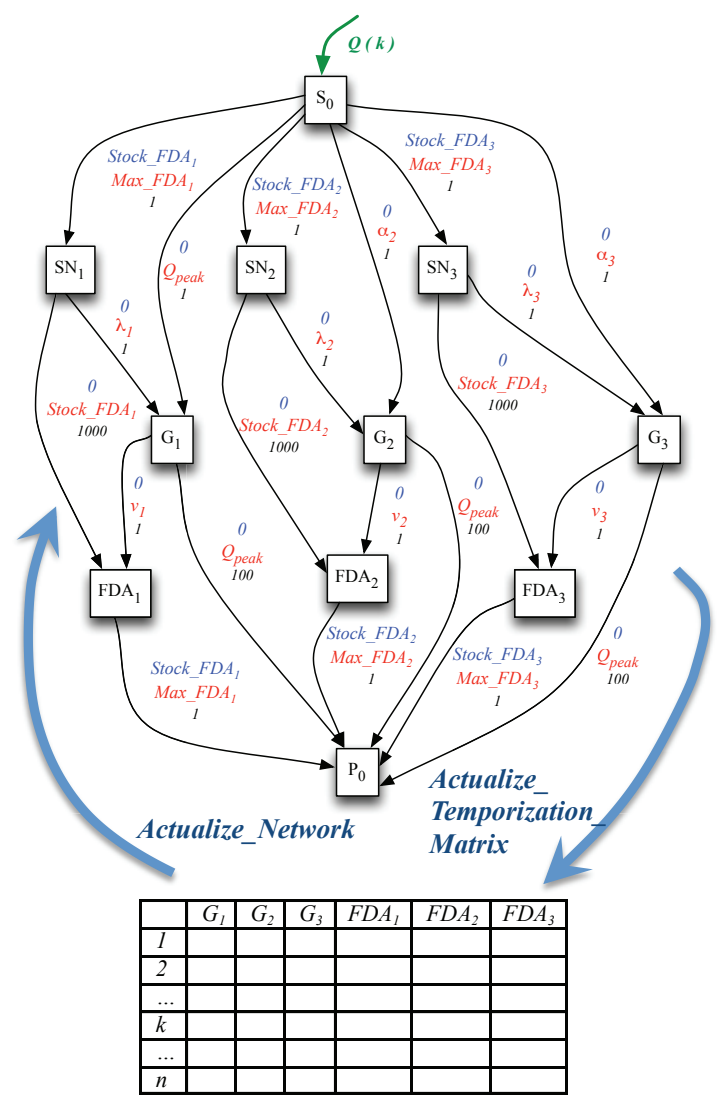

Figure 2. Dynamic RGTM mechanism

evolution of the state of our flood-diversion area system. $\mathbb{R} \mathbb{G}=\{\mathcal{R N}, \mathcal{R} \mathcal{A}\}$ where $\mathcal{R} \mathcal{N}$ is a set of $3 n_{G}+2$ nodes defined as follows:

- $G_{r}$ represents the gate, with $r=1, \cdots, n_{G}$;

- $S N_{r}$ is a bifurcation node, with $r=1, \cdots, n_{G}$;

- $F D A_{r}$ represents the flood lamination area with $r=1, \cdots, n_{G}$;

- $S_{0}$ is a source node corresponding to the fictive entry point of our FDAs system;

- $P_{0}$ is a sink node corresponding to the fictive exit point of our FDAs system.

These nodes are associated to the set of valued arcs $\mathcal{R} \mathcal{A}$, describing the following connections:

- Between nodes $S_{0}$ and $S N_{r}, r=1, \ldots, n_{G}$, it represents the water volume already stored in the $F D A_{r}$ linked to it.

- Between nodes $S N_{r}$ and $G_{r}, r=1, \ldots, n_{G}$, it represents the draw-off flow leaving the $F D A_{r}$ towards the gate $G_{r}$ at the concerned period.

- Between nodes $S N_{r}$ and $F D A_{r}, r=1, \ldots, n_{G}$, it represents the water volume remaining in the $F D A_{r}$ at the end of the concerned period. 
- Between nodes $S_{0}$ and $G_{r}$, with $r=2, \cdots, n_{G}$, takes into account at initialization the discharge upstream the gate $G_{r}$ in the FDAs system.

- Between nodes $G_{r}$ and $F D A_{r}$, connects each gate with its FDA, and represents the flow crossing the gate $G_{r}$ towards the $F D A_{r}$ at the end of each period $k$.

- Between $G_{r}$ and $P_{0}$, with $r=1, \cdots, n_{G}-1$, it represents the flow transferred to following gate $G_{r+1}$. This discharge is stored in the column associated to gate $G_{r+1}$ at line $k+k_{r}$ with $\tau_{r}=$ $k_{r} T_{c}$

- Between $G_{n_{G}}$ and $P_{0}$, the flow-rate downstream the exit point of our FDAs system when this discharge is not stored in the $F D A_{n_{G}}$

- Between nodes $F D A_{r}$ and $P_{0}$, it takes into account the available water volume stored in the $F D A_{r}$ at the end of the concerned period

In Figure 2, for each arc, its maximum capacity is written in blue, its minimum capacity is written in red and its cost is written in black. All these arc values are used by the Flood-Lamination algorithm described in algorithm 1 in order to derive the gate opening set-point values. In the Flood-Lamination algorithm, after an initialization phase, at each $k$, the network is actualized (see algorithm 2), the optimal flow is computed and the temporization matrix is actualized (see algorithm 3). In order to compute the optimal flow, the Min cost Max flow problem resolution for this reduced size temporized network is done, using a Linear Programming formulation (as described in [13]), according to our management objectives. In the algorithms:

- $Q(k)$ is the flow-rate entering the network at $k T_{c}$. At $k$, it corresponds to the sum of flows entering the gates added to the sum of the water volumes stocked in all FDAs turned into discharges.

- $Q_{\text {peak }}$ is the maximum peak flow-rate of flood scenario.

- $M a x_{-} F D A_{r}$ is the maximum storage capacity of $F D A_{r}$, it depends on $Q_{\text {peak }}$.

- $\nu_{r}$ is the maximal capacity on the arc between the gate $G_{r}$ and the $F D A_{r}$.

- $\lambda_{r}$ is the maximal capacity on the arc between the node $S N_{r}$ and the gate $G_{r}$.

- The storage phase and release phase cannot occur at the same time for one gate. This is govern by the use of $\mu_{r}$ and $\gamma_{r}$ coefficients with

$$
\begin{cases}\gamma_{r}=1, \mu_{r}=0 & \text { storage in } F D A_{r} \\ \mu_{r}=1, \gamma_{r}=0 & \text { release from } F D A_{r} \\ \gamma_{r}=0 & \text { no storage in } F D A_{r} \\ \mu_{r}=0 & \text { no release from } F D A_{r}\end{cases}
$$

- $Q_{\text {lam }}$ is the lamination flow-rate chosen by the river system manager and defined as the flow level at which the river flow-rate must be laminate, i.e. the hydraulic set point over the foreseen horizon $H_{f}$.

- $Q_{d o}$ is the discharge level under which the FDA draw-off is done.

- Stock_FDA $A_{r}$ is the minimum capacity on the arc between the source $S_{0}$ and the $F D A_{r}$. It corresponds to the amount of water already present in the $F D A_{r}$.

During the phase one of the initialization of the Flood-Lamination algorithm, the first column of $T M$ matrix is set to the value of the flow-rate upstream the river at each $k T_{c}(k=1, \cdots, n)$, which is the flow-rate upstream the first gate $G_{1}$. The initialization phase two allows to introduce discharge values upstream all the gates $G_{r}\left(r=2, \cdots, n_{G}\right)$ during the non stationary phase i. e. before $k=k_{n_{G}-1}$, with $\tau_{n_{G}-1}=k_{n_{G}-1} T_{c}$. We choose in this case to set these upstream discharges to the flow-rate upstream the river except when it is higher than the lamination flow-rate. In the Actualization Network algorithm described in algorithm 2 , the network $\mathbb{R} \mathbb{G}$ is updated at each $k T_{c}(k=1, \cdots, n)$. The network parameters values at $k-1$ such as adjacency matrix, costs and constraint vector (arc minimum and maximum values) are provided as input parameters. The strategy parameters, $\gamma_{r}$ and $\mu_{r}$ are set depending on the discharge values in the matrix $T M$. The flow entering the network is updated with the sum of the line $k$ of the $T M$ matrix. In order to take into account the transfer time between gates, the maximum flow-rate upstream each gate $G_{r}\left(r=2, \cdots, n_{G}\right), \alpha_{r}$, is set to the $T M$ matrix stored value at previous time. The maximum capacity of the $\operatorname{arc}\left(G_{r}, F D A_{r}\right), \nu_{r}$, is set to the amount of flow-rate overtaking $Q_{\text {lam }}(k)$ lower than the remaining $F D A_{r}$ capacity (only if the $F D A_{r}$ can be used i. e. $\gamma_{r}=1$. The value of Stock $F D A_{r}$ is set to its previous value stored in the $T M$ matrix. Finally, the maximum capacity of the $\operatorname{arc}\left(S N_{r}, G_{r}\right), \lambda_{r}$, is set to the amount of flow-rate overtaking $Q_{\text {lam }}(k)$ lower than the remaining $F D A_{r}$ capacity (only if the $F D A_{r}$ can be used i. e. $\gamma_{r}=1$. In the Actualization Temporization Matrix algorithm described in algorithm 3 , the matrix $T M$ is updated at each $k T_{c}$ $(k=1, \cdots, n)$. In this matrix, the temporized flow values are stored and actualized such that transfer times can be introduced in the network. In order to 


\begin{tabular}{c}
\hline Algorithm 1: Flood lamination \\
input :
\end{tabular}

$\mathbb{R} \mathbb{G}$ the reduced transportation network

$n=E\left(\frac{H_{f}}{T_{c}}\right)+1$ the number of samples

$n_{G}$ the numbers of gates and FDA in the river system

$k_{r}$ such that $\tau_{r}=k_{r} T_{c}, r=1, \cdots, n_{G}-1$

$Q_{\text {input }}(k)$ the flow of flood scenario at $k T_{c}$ for $k=1 \cdots n$

$Q_{\text {lam }}$ the lamination flow

output:

$\mathbb{R} \mathbb{G}$ the reduced transportation network

$T M$ the $n \times 2 n_{G}$ temporization matrix

$\varphi$ the optimal flow for each arc in the network $\mathbb{R} \mathbb{G}$

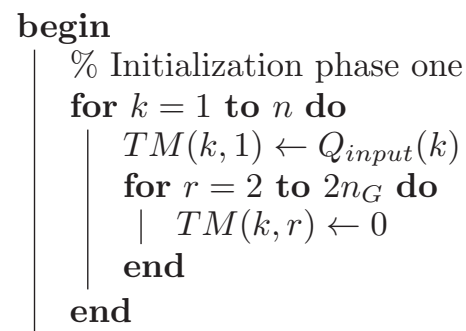

$\%$ Initialization phase two

for $r=1$ to $n_{G}-1$ do

for $k=1$ to $k_{r}$ do

$T M(k, r+1) \leftarrow$

$\min \left(Q_{\text {input }}(1), Q_{\text {lam }}\right)$

end

end

$k \leftarrow 1$

while $(k \leq n)$ do

Actualize_Network $(\mathbb{R G}, k, T M)$

$\varphi(k) \leftarrow$

Compute_Optimal_Flow $(\mathbb{R} \mathbb{G}, k)$

Actualize_Temporization_Matrix $(\varphi(k), k, T M)$

$k \leftarrow k+1$

end

end

take into account the transfer time between gates, the optimal flow from each gate $G_{r}\left(r=1, \cdots, n_{G}-1\right)$ to the sink $P_{0}, \varphi_{\left(G_{r}, P_{0}\right)}(k)$, is stored in the $T M$ matrix as the future discharge upstream the following gate $G_{r+1}$ at $k+k_{r}$. The flow feeding each $F D A_{r}$ $\left(r=1, \cdots, n_{G}\right)$ at $k, \varphi_{\left(F D A_{r}, P_{0}\right)}(k)$, is added to the flow already stored in order to obtained the new stored value. This value is written in the $T M$ matrix as the future $F D A_{r}$ stored value i. e. at $k+1$. A co-

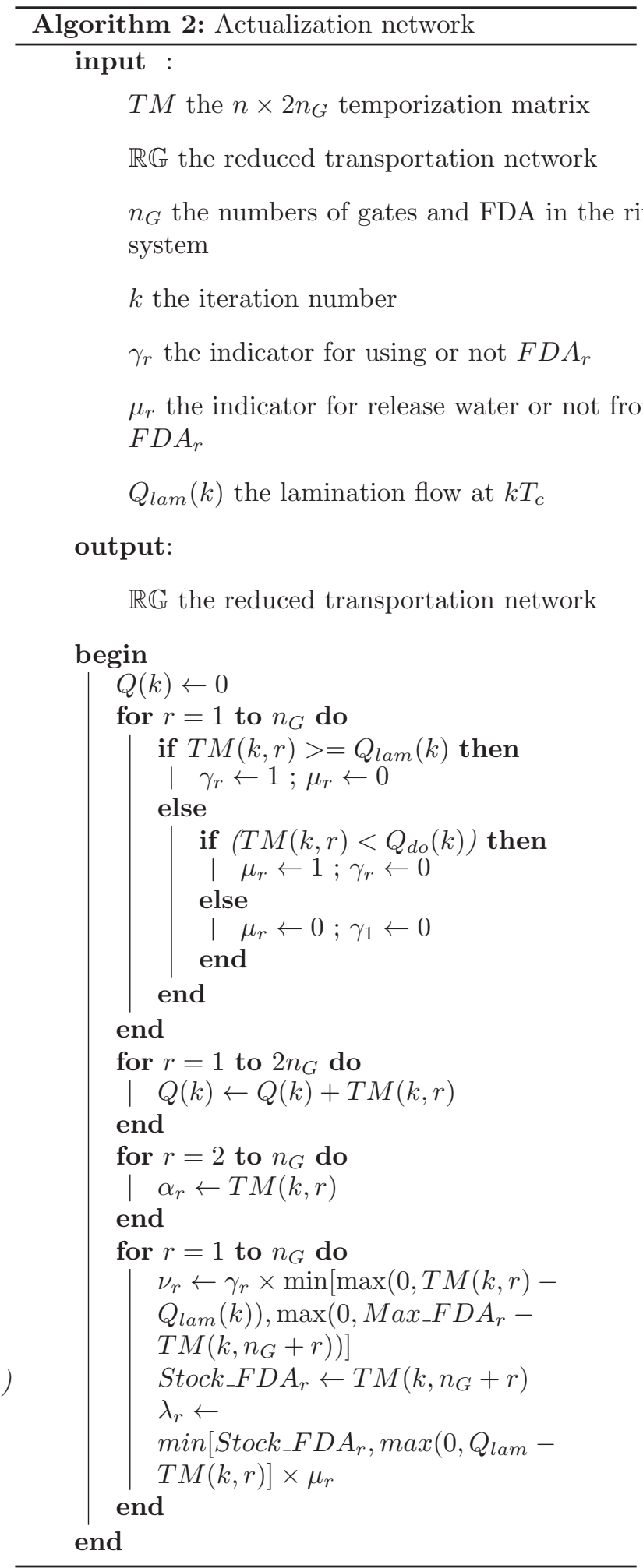

operation has been established between the dynamic RGTM mechanism and the 1D simulator (developed by [7]), in order to update flow and water quantity stocked with measured values. The scheme used is given in Figure 3 and the algorithm for actualization of temporized matrix is modified as given in algorithm 4. 

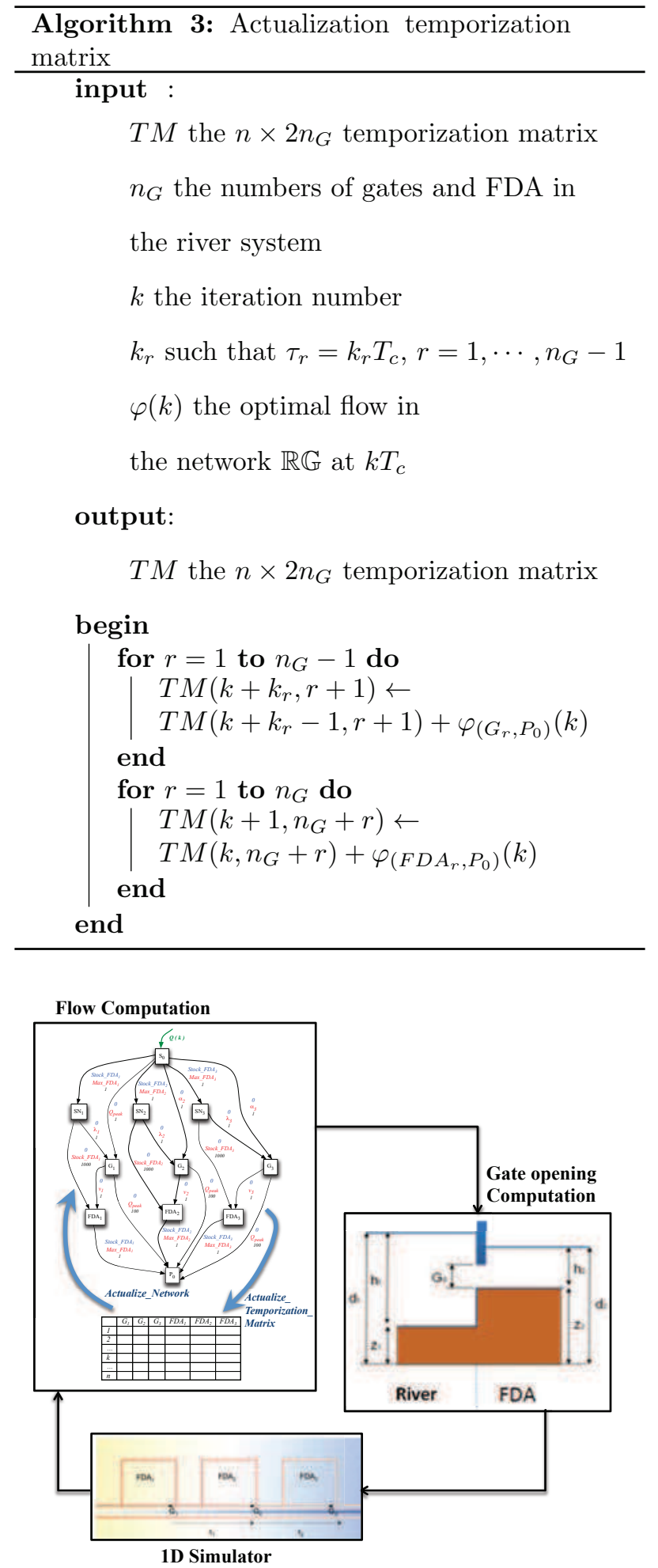

\section{Figure 3. Dynamic RGTM mechanism and 1D simulator cooperation}

\section{COMPUTATIONAL RESULTS}

We present some results obtained using the dynamic RGTM mechanism cooperating with the 1D

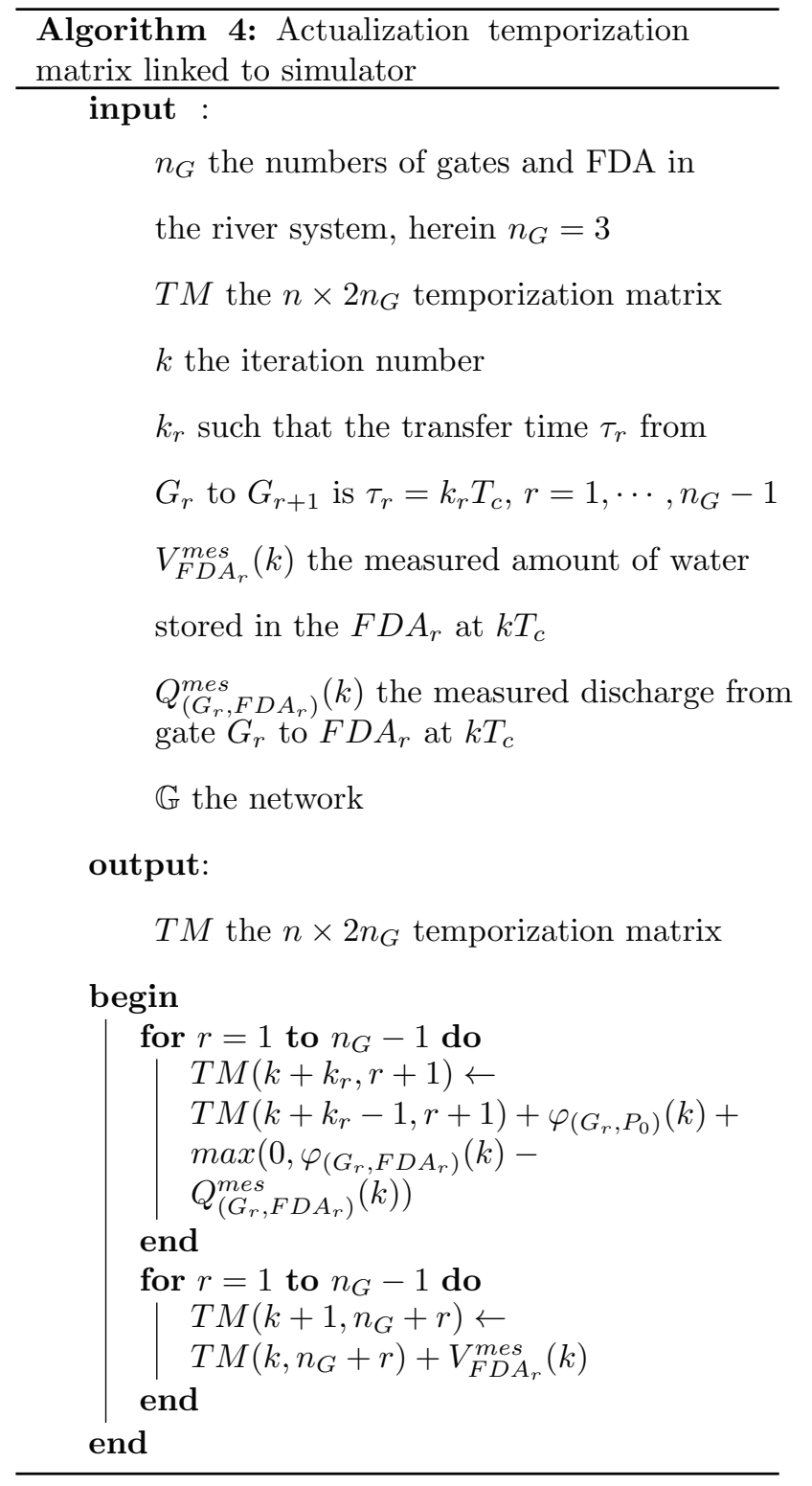

hydraulic simulator as described in section 2. At each $T_{c}$, an input hydrograph representing usual encountered cases is sent to the 1D simulator (see Figure 3 ). The actual levels along the river and in the FDAs are computed thanks to this hydraulic simulator and sent to the RGTM program. It computes the flow to be sent in each FDA. These values are transformed in height by the gate opening computation block. The gates opening values are then given as input to the 1D simulator. All values are registered and plotted in the figures displayed in this section.

In figure 4 are given in red the $Q_{\text {input }}$ value, in green the $Q_{\text {ouput }}$ value with gates always opened (unregulated reservoirs), in black the $Q_{\text {output }}$ value when the strategy is applied with $Q_{\text {lam }}=675 \mathrm{~m}^{3} / \mathrm{s}$ and $Q_{d o}=600.6 \mathrm{~m}^{3} / \mathrm{s}$. The time delay values where set to $\tau_{1}=10 T_{c}$ and $\tau_{2}=9 T_{c}$, with $T_{c}=100 \mathrm{~s}$. For these values, the discharge remains under the $Q_{\text {lam }}$ 


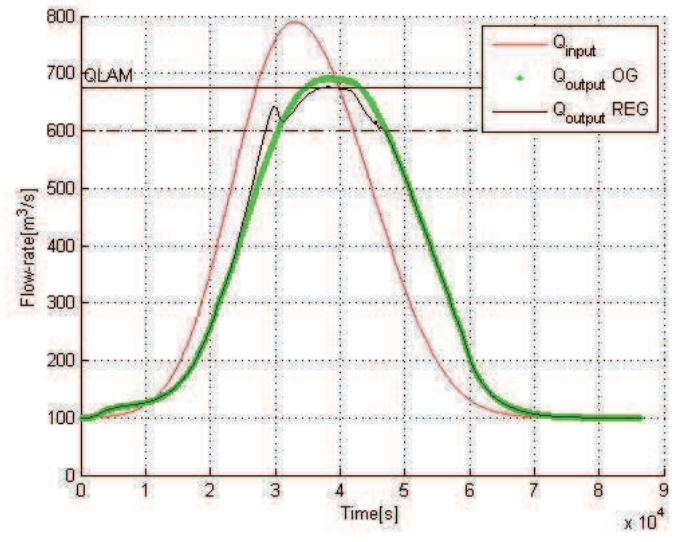

Figure 4. $Q_{\text {input }}$ and $Q_{\text {output }}$ for $Q_{\text {lam }}=$ $675 \mathrm{~m}^{3} / \mathrm{s}, Q_{d o}=600.6 \mathrm{~m}^{3} / \mathrm{s}$ and open gates

value, and the draw-off begins at $k=432$ when the discharge is under the value of $Q_{d o}$. On the contrary, when gates are always opened it is not possible to avoid flood dowstream, in fact the discharge overstep the $Q_{l a m}$ value. In figures 5, 6 and 7 are represented in blue the gates opening height computed by the algorithm, in black the water level inside the FDA (backward the gate) and in red the water level in the river forward the gates, for respectively gates 1,2 and 3 . The water levels are measured with regard to the river bed. On each figure, the gate is firstly opened in order to store water, thereafter, during the phase when the discharge is between $Q_{l a m}$ and $Q_{d o}$ the gate is closed and finally, the gate is opened in order to empty the FDA.

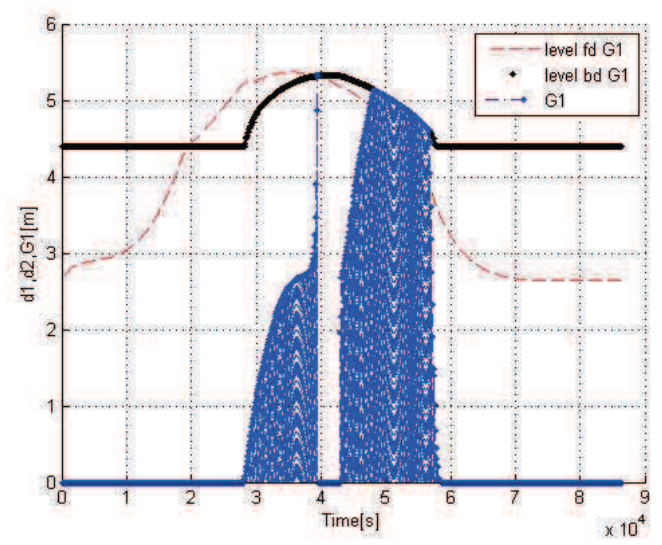

\section{Figure 5. First gate opening and water levels inside and outside $F D A 1$}

In order to show the benefits of our strategy compared to strategy were all gates are always opened during the concerned horizon, the water level inside the FDA are superimposed in figures 8, 9 and 10

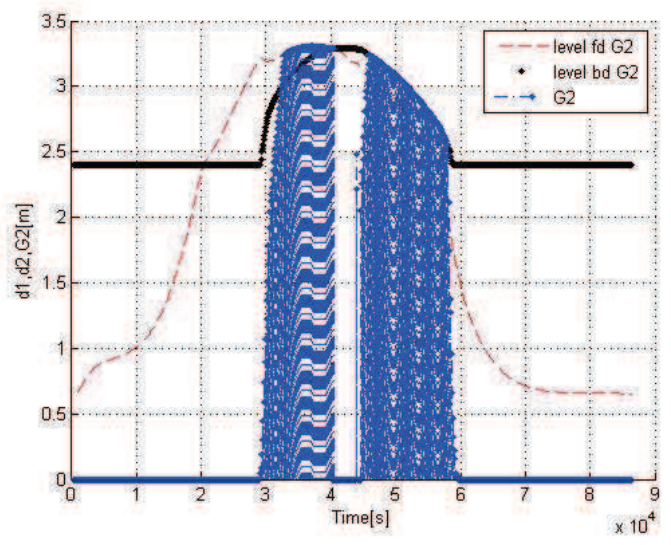

Figure 6. Second gate opening and water levels inside and outside $F D A 2$

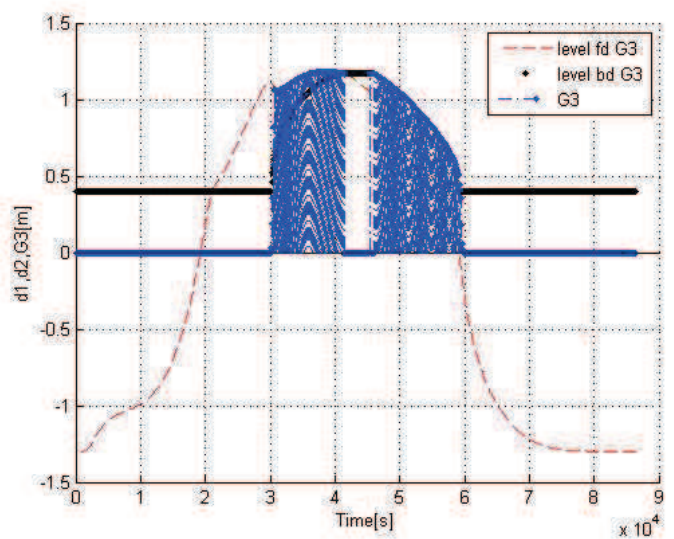

Figure 7. Third gate opening and water levels inside and outside $F D A 3$ 
where our strategy is in black and the gates always opened are in green. For the three gates, the green curve is always upper the black one, that means that the reservoirs capacity should be more important in the always open gates cases. Furthermore the FDA are filled earlier in the always open gates strategy. The proposed RGTM strategy allows to better preserved the agricultural zones used as flood diversion areas. If the slope of the water level is found to be too important so that is can affect the fertility of the flood diversion area, it should be considered as a new decision criterion to include in the dynamic RGTM method.

In figure 11 are compared results obtained with two different $Q_{d o}$ values: in black $Q_{d o}=600.6 \mathrm{~m}^{3} / \mathrm{s}$ and in blue $Q_{d o}=500 \mathrm{~m}^{3} / \mathrm{s}$. In the case where $Q_{d o}=$ $600.6 \mathrm{~m}^{3} / \mathrm{s}$, the FDA is emptied earlier. The choice of the $Q_{d o}$ can be driven by the nature of the cultivation done in the FDA. Moreover, it is possible to decide to empty the FDA as soon as possible in order to be able to absorb a further flood.

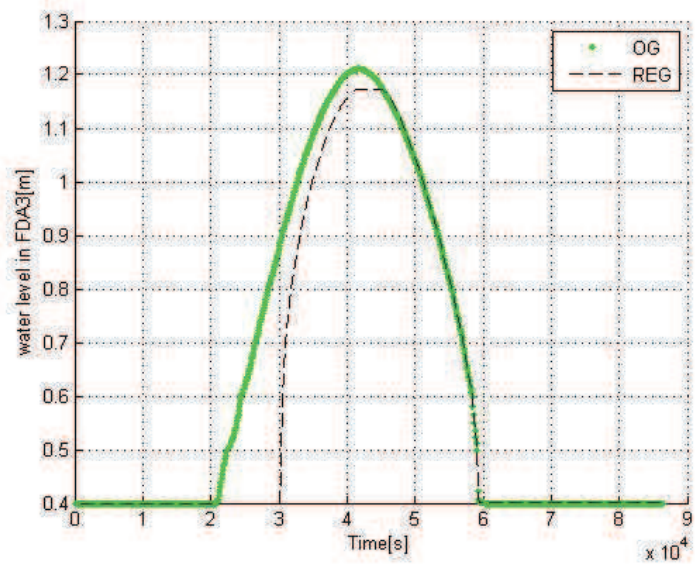

Figure 8. Water levels inside the $F D A_{1}$ for open and regulated gates. $Q_{l a m}=675 \mathrm{~m}^{3} / \mathrm{s}$, $Q_{d o}=600.6 \mathrm{~m}^{3} / \mathrm{s}, \tau_{1}=10 T_{c}, \tau_{2}=9 T_{c}$

\section{Conclusion}

A water storage and release strategy was presented in order to perform flood lamination of a river system equipped with flood diversion areas. The strategy is based on a dynamic mechanism combining a Reduced Graph and a Temporization Matrix. It allows to account for time delay without using expanded graph usually performed in this context. The results of the collaboration between this mechanism and the 1D simulator of river were given, highlighting the benefits of the strategy. Namely, during storage phase, the strategy allows for remaining under the lamination discharge level imposed: the flood is laminated,

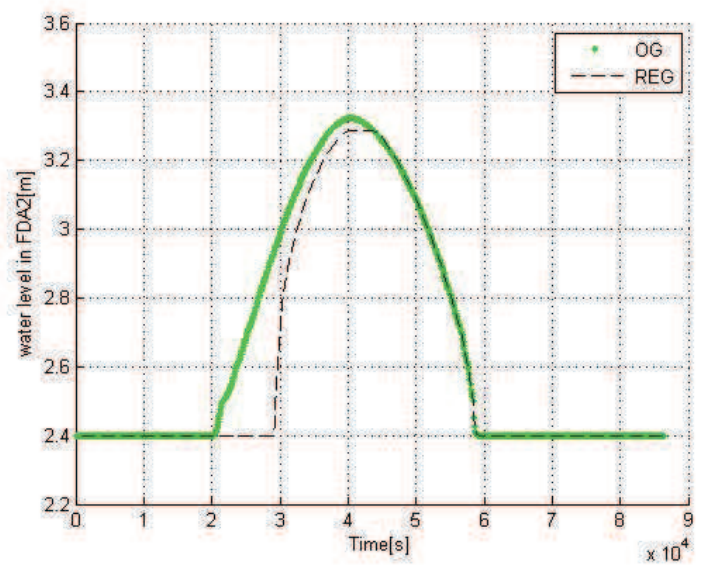

Figure 9. Water levels inside the $F D A_{2}$ for open and regulated gates. $Q_{l a m}=675 \mathrm{~m}^{3} / \mathrm{s}$, $Q_{d o}=600.6 m^{3} / s, \tau_{1}=10 T_{c}, \tau_{2}=9 T_{c}$

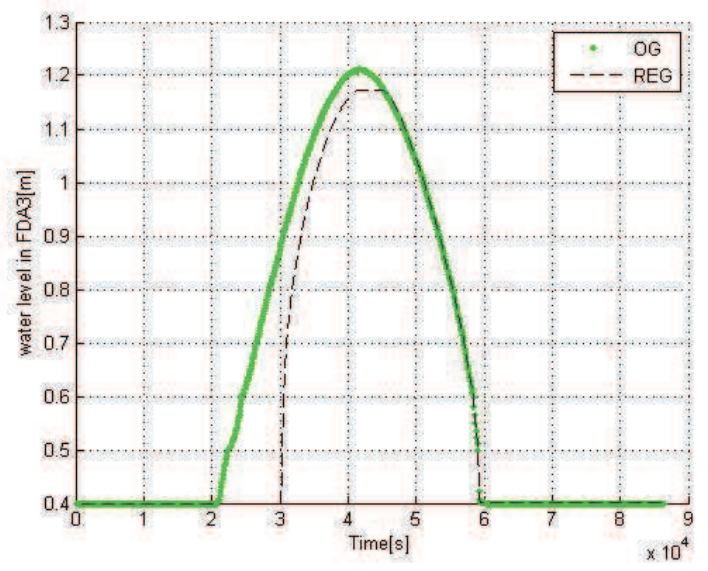

Figure 10. Water levels inside the $F D A_{3}$ for open and regulated gates. $Q_{l a m}=675 \mathrm{~m}^{3} / \mathrm{s}$, $Q_{d o}=600.6 \mathrm{~m}^{3} / \mathrm{s}, \tau_{1}=10 T_{c}, \tau_{2}=9 T_{c}$ 


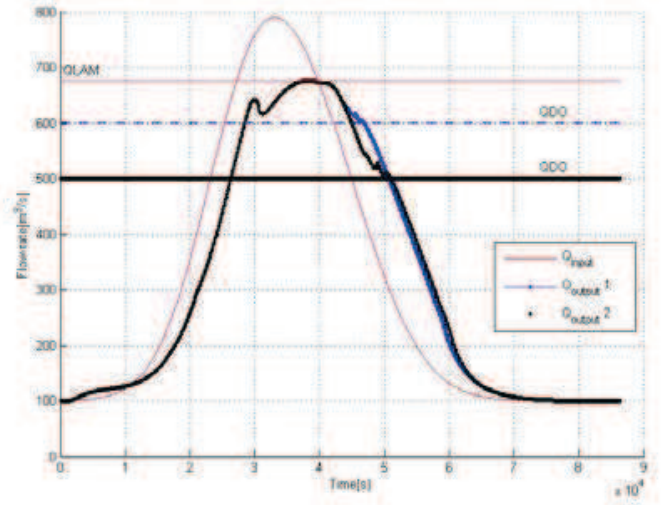

Figure 11. $Q_{\text {input }}$ and $Q_{\text {output }}$ for $Q_{\text {lam }}=$ $675 \mathrm{~m}^{3} / \mathrm{s}, Q_{d o}=600.6 \mathrm{~m}^{3} / \mathrm{s}$ and $Q_{d o}=$ $500 \mathrm{~m}^{3} / \mathrm{s}$

and during the draw-off phase, Flood Diversion Areas are preserved. The strategy can be used in order to estimate the capability of the river system equipped with flood diversion areas to take over floods. Beyond a quantitative flood management an important problem to address is the quality of water in the river and in the FDAs. Future work will focus on the integration of pollution problems in the strategy.

\section{Acknowledgments}

The authors want to thank Confederacin Hidrogrfica del Ebro for providing the case study used in this paper as well as for sharing their hydrological management expertise and Fluid Mechanics, LIFTECEINA, University of Zaragoza for providing the 1D simulator.

\section{References}

[1] R. K. Ahuja, T. L.Magnanti, and J. B. Orlin. Network Flows: Theory, Algorithms, and Applications. Prentice-Hall, Inc.Upper Saddle River, NJ, USA, 1st edition, 1993.

[2] A. Bemporad, A. Casavola, and E. Mosca. Nonlinear Control of Constrained Linear Systems via Predictive Reference Management. IEEE Transactions On Automatic Control, 42(3):340-349, 1997.

[3] D. P. Bertsekas. Linear Network Optimization. The MIT Press, Cambridge, Mass, USA., 1991.

[4] X. Cai, D. C. McKinney, and L. S. Lasdon. Solving nonlinear water management models using a combined genetic algorithm and linear programming approach. Advances in Water Resources, 24(6):667676, June 2001.

[5] C. A. Floudas, A. Aggarwal, and A. R. Ciric. Global optimum search for nonconvex NLP and MINLP problems. Computers \&5 Chemical Engineering, 13(10):1117-1132, 1989.
[6] G. Fu. A fuzzy optimization method for multicriteria decision making: An application to reservoir flood control operation. Expert Systems with Applications, 34(1):145-149, Jan. 2008.

[7] P. Garcia-Navarro, P. Brufau, J. Burguete, and J. Murillo. The shallow water equations: An example of hyperbolic system. Monografias de la Real Academia de Ciencias de Zaragoza, 31:89-119, 2008.

[8] M. Gondran and M. Minoux. Graphs and Algorithms. Eyrolles, Paris, France, 3rd edition, 1995.

[9] E. Köhler, K. Langkau, and M. Skutella. Timeexpanded graphs for flow-dependent transit times. In Procceedings 10th Annual European Symposium on Algorithms, pages 599-611, 2002.

[10] D. R. Kracman, D. C. McKinney, D. W. Watkins Jr., and L. S. Lasdon. Stochastic Optimization of the Highland Lakes System in Texas. Journal of Water Resources Planning and Management, 132(2):62-70, 2006.

[11] V. Melkonian. Flows in dynamic networks with aggregate arc capacities. Information Processing Letters, 101(1):30-35, Jan. 2007.

[12] J. T. Needham, D. W. Watkins Jr., J. R. Lund, and S. K. Nanda. Linear Programming For Flood Control In The Iowa And Des Moines Rivers. Journal Of Water Resources Planning And Management, 126(3):118-127, 2000.

[13] H. Nouasse, P. Charbonnaud, P. Chiron, J. Murillo, M. Morales, P. Garcia-Navarro, and G. Perez. Flood lamination strategy based on a three-flooddiversion-area system management. In 2012 20th Mediterranean Conference on Control \& Automation (MED), pages 866-871, Barcelona, July 2012. IEEE.

[14] H. Nouasse, P. Chiron, and B. Archimède. A flood lamination strategy based on transportation network with time delay. Water Science Technology Water Supply, in Press, 2013.

[15] X. J. Wang, R. H. Zhao, and Y. W. Hao. Flood Control Operations Based on the Theory of Variable Fuzzy Sets. Water Resources Management, 25(3):777-792, Jan. 2011. 